\title{
A tribute to Christopher Gunapala Uragoda
}

In every profession there are individuals, who in their lifetime, are justifiably accorded a historical position and recognition because of their achievements and the impact they make on their peers, Dr. Christopher Gunapala Uragoda is one such person. He is an accomplished, distinguished and humble man. He is a clear thinker with a warm heart, a cool head and a quiet disposition. By all standards Dr. Uragoda is a remarkable professional, and he can truly be described as a colossus in the medical profession. Dr. Uragoda (or Chris as he is endearingly referred to by his colleagues and friends), a qualified MBBS (Ceylon), is now an MD (Ceylon), Hon. DSc (Colombo), FRCP (Edin), FRCP (Glasg), Fellow of the American College of Chest Physicians, Fellow of the Faculty of Occupational Medicine of the Royal College of Physicians, London, Fellow of the Ceylon College of Physicians; Fellow of the National Academy of Sciences of Sri Lanka, and Honorary Fellow of the College of General Practitioners of Sri Lanka

He was born in Hikkaduwa in 1928 and had his early education in three schools: Richmond, Mahinda and
Ananda. Thereafter he joined the Faculty of Medicine of the University of Ceylon, from where he obtained the MBBS degree in 1953. Except for a brief period of 3 months when he was District Medical Officer, Pallebedde, throughout his professional career Chris has practiced respiratory medicine. He was Physician-in-Charge, Central Chest Clinic, Colombo and Physician at Chest Hospital, Welisera. He served as a Consultant Chest Physician in England for 6 months, but preferred to discontinue and come back to Sri Lanka.

Dr. Uragoda has received prestigious awards for research, namely the Guinness Award in 1980, Peter Pillai Award in 1981, President's Award of the National Research Education and Science Authority (offered once in three years) in 1996, and the Sarvodaya Award in 1999. He was elected through distinction, a Member of the Faculty of Occupational Medicine of the RCP London, and was a member of the WHO Expert Panel on Tuberculosis for 20 years. He has delivered several orations and prestigious lectures, including the Convocation Address of the University of Colombo. 
Dr. Uragoda has held important offices in national associations and professional bodies wherein he has made significant contributions. He has at various times been the President of the Sri Lanka Medical Association, Ceylon College of Physicians, Kandy Society of Medicine, Sri Lanka Medical Council and Chairman of the Ceylon National Association for the Prevention of Tuberculosis.

He held the office of the President of the Royal Asiatic Society for more than 5 years, being the first medical doctor to hold this office in over 125 years. The Society awarded him the Hilda Obeysekera Medal, which has been won by a handful of men such as Paul E Pieris, RL Brohier and Bishop Edmund Pieris. He was the Joint Editor of the Ceylon Medical Journal for 20 years, as well as the Journal of the Ceylon College of Physicians and Journal of the National Academy of Sciences. Dr. Uragoda is a prodigious author who writes in an inimitable, delightfully readable style. His prose has a classical elegance that few can match. He is a unique individual who not only wrote on history, but also created history during his productive life.

His research interests include both medical and nonmedical subjects. The main area of medical research has been occupational lung disease. Traditional industries, which have been neglected by workers throughout the world at the time he investigated them, formed the cornerstone of his research. He was the first ever to study diseases caused by dust emanated by chilli, tea, kapok, cinnamon, coir, ilmenite, and activated carbon. He described for the first time the relationship between pulmonary tuberculosis and exposure to graphite dust. Chris became interested in research in occupational lung disease when he "developed a curiosity as to why is it as it is" something which Robert Westbury terms, the "WIGO Flash" "What is Going On?"

To quote Dr. Uragoda, "When I was working in Kandy, I used to go to a chilli-grinding mill to purchase my household requirement of chilli powder. As soon as I stepped into the premises, I was assailed by bouts of coughing and sneezing, while the workers inside were unaffected. This induced me to investigate the reason why." (Chris's study on chilli grinders, published in the British Journal of Industrial Medicine in 1967 showed that the symptoms were maximal at the beginning of employment and that tolerance developed after 3 days to 6 months. The interesting feature was that this sequence was contrary to the usual pattern in occupational lung disease where the condition develops after years of exposure and gets worse on further exposure.

Though Sri Lanka has been world renowned for $1 \frac{1}{2}$ century as the land of tea, Uragoda became the first to publish a paper (in Thorax) on occupational lung disease caused by tea dust. It reveals fertile and inquiring mind endowed with "WIGO Flash" that he has. Uragoda published several papers on tuberculosis, but the one he wrote jointly with Professor SR Kottegoda is the most important one. They found that tuberculosis patients on isoniazid get a histamine reaction on eating the fish, skipkack
(Balaya). Their research revealed that skipjack was rich in histamine and that isoniazid prevents its destruction, thus increasing skipjack poisoning. Dr. Uragoda has contributed chapters to several books, which include the prestigious Oxford Textbook of Medicine, Handbook of Drug Reactions, Occupational Heath in Developing Countries and Philanthropy and Cultural Context, all of which have been published abroad.

Extensive reading of old books and articles on Sri Lanka enabled him to embark on a book, A History of Medicine in Sri Lanka, which got published in 1987 as the centenary publication of the Sri Lanka Medical Association. It is a widely quoted reference book that has earned Chris a justifiable place in the history of medical publications. A bibliography of medical publications relating to Sri Lanka was published in three volumes, covering the periods 1811-1976, 1977-1980 and 1981-1988. The first two of these were co-authored with Kamalika Peiris. The entries listed include abstracts as well. This bibliography, a truly monumental work, has proved to be of immense value to medical researchers and is widely cited.

In addition to books on medicine, he wrote widely on non-medical subjects. His interest in the jungles of Sri Lanka, where he used to camp from 1953 onwards, provided him with the subject for two books. In 1994 he authored Wildlife Conservation in Sri Lanka, the centenary publication of the Wildlife and Nature Protection Society of Sri Lanka. The other book, Jungle Journeys in Sri Lanka. Experiences and Encounters, was edited by him and contained contributions from 15 well-known jungle lovers including himself. Published in 2004, it opened the door to the younger generations to learn about jungle life 50 years ago.

In 1995, Dr. Uragoda co-edited with GPSH de Silva the monumental Sesquicentennial Commemorative Volume of the Royal Asiatc Society of Sri Lanka 18451995. This 590-page book contains articles from 21 contributors who are all specialists. In 2000 Chris published Traditions of Sri Lanka, A Selection With a Scientific Background. This was the first book on the subject in Sri Lanka. Its objective was to provide a scientific rationale for some of our traditions, and thereby highlight the innate wisdom of our forebears. The book had its origin in Chris's discovery that skipjack, which is traditionally believed to be "heaty", is the richest histamine-containing food in the world. If high histamine content is interpreted as being equal to "heatiness", then there is some truth in this tradition.

Over the years Chris has helped to improve the quality of medical writing in Sri Lanka. In his modest and gentle style he often guides novice writers willingly and ably. Several authors and speakers have conveyed their thanks to Chris for guiding them in making fine and lucid presentations.

He is gifted with the potential for making changes, rephrasing sentences and paragraphs, correcting mistakes and at the same time in no way making the writer feel degraded. The manner in which he converts a mundane, 
badly written article into an elegant document is a treat to witness. To strike a personal note, over the past three decades I have never ever published an article without Chris having run his editorial pen on it and made the required corrections.
Dr. Christopher Gunapala Uragoda is an altruistic gentleman. He has achieved much and yet continues to be humble and soft spoken. He is an adornment to the medical profession.

Dennis J Aloysius, Family Physician, Ratmalana, Sri Lanka. E-mail:<djaloy@eureka.com> (Competing interests: none declared). 